\title{
Inflight Vertical Antenna Patterns for SIR-C from Amazon Rain-Forest Observations
}

\author{
Yujun Fang and Richard K. Moore \\ University of Kansas, Radar Systems and Remote Sensing Laboratory \\ 2291 Irving Hill Road, Lawrence, KS 66045-2969, USA \\ TEL: 913/864-4836 , FAX: 913/864-7789 , E-mail: rmoore@eecs.ukans.edu
}

Abstract-We measured the vertical pattern of the Shuttle Imaging Radar C (SIR-C) antenna using images of the Amazon rain forest, the largest flat and homogeneous forest in the world. Its scattering coefficient is nearly independent of the incidence angle $[1,2]$. The images produced by JPL use the standard SIR-C CEOS format. We must use images without radiometric correction to get the antenna pattern, as the radiometric correction depends on preflight patterns. We can only give a small sample of the patterns for the SIR-C antenna in this paper, as the number of Amazon passes was limited, and only a few of the many modes were available. For both $\mathrm{L}$ band and $\mathrm{C}$ band all possible linear polarizations could be used. In addition, electronic beam steering up to $\pm 20^{\circ}$ from the boresight direction [3] could modify the patterns. Also nine "beam spoiling" modes could change the patterns. We previously reported on the SIR-B [4] and XSAR patterns [5] obtained by the same method.

If all modes had been tested over the Amazon or some other suitable homogenous area, we would have been able to give details of all patterns. Unfortunately the number of passes over suitable areas was very limited, so we can only report on those passes.

\section{IMAGE SELECTION}

Regions with homogeneous scattering coefficient can be used to extract the vertical antenna pattern of the antenna. Patterns presented here are from images collected during the first SIR-C/X-SAR mission in April, 1994, from passes 39.60, 55.62, 78.60 and 103.60. We removed segments showing evidence of hills or extensive water areas before processing for the antenna pattern. Table 1 summarizes the image data used.

Table 1. Summary of Image Data Used

\begin{tabular}{|c|c|c|c|c|c|c|c|}
\hline $\begin{array}{l}\text { Product } \\
\text { ID }\end{array}$ & $\begin{array}{l}\text { Data } \\
\text { Take } \\
\text { ID }\end{array}$ & $\begin{array}{l}\text { Sile } \\
\text { Name }\end{array}$ & Letitude & Longitude & $\begin{array}{l}\text { Inc. } \\
\text { Ang. }\end{array}$ & $\begin{array}{l}\text { Beam } \\
\text { Spoiling } \\
\text { Mode }\end{array}$ & $\begin{array}{l}\text { Beam } \\
\text { Steering } \\
\text { Angle }\end{array}$ \\
\hline 11.389 & 39.6 & Amazon C. & $50^{\circ} .32^{\circ}$ & $w 70^{\circ} \cdot 12^{\circ}$ & $44.0^{\circ}$ & 0 & $2.2^{\circ}$ \\
\hline 11.390 & 39.6 & Amazon C. & S $22^{\circ}-40^{\circ}$ & $W 68^{\circ} .24^{\circ}$ & $44.0^{\circ}$ & 0 & $2.1^{\circ}$ \\
\hline 11.342 & 55.62 & $\begin{array}{l}\text { Amazon } \\
\text { Cal. }\end{array}$ & $N O^{\circ}-41^{\circ}$ & $W 69^{\circ} \cdot 19^{\prime}$ & $26.3^{\circ}$ & 0 & $14.7^{\circ}$ \\
\hline 12.347 & 78.6 & $\begin{array}{c}\text { Amazon } \\
\text { Cal. }\end{array}$ & $58^{\circ} \cdot 10^{\prime}$ & $W 62^{\circ}-26^{\circ}$ & $29.8^{\circ}$ & 6 & $11.3^{\circ}$ \\
\hline 12,348 & 78.6 & $\begin{array}{c}\text { Amazon } \\
\text { Cal. }\end{array}$ & $S 7^{\circ} \cdot 22^{\prime}$ & $W 61^{\circ}-58^{\circ}$ & $29.8^{\circ}$ & 6 & $11.3^{*}$ \\
\hline 12.092 & 103.6 & $\begin{array}{c}\text { Sen } \\
\text { Madurein }\end{array}$ & S $21^{\circ}-20^{\circ}$ & $W 60^{\circ}-48^{\prime}$ & $48.7^{\circ}$ & 0 & $6.4^{\circ}$ \\
\hline 12.093 & 103.6 & $\begin{array}{c}\text { Sena } \\
\text { Madurein }\end{array}$ & $S 21^{\circ}-20^{\circ}$ & $W 60^{\circ}-48^{\circ}$ & $48.7^{\circ}$ & 0 & $6.4^{\circ}$ \\
\hline
\end{tabular}

Latitudé, longitude and incidence angle are defined at the center of the image.

\section{METHODOLOGY}

We first averaged in both along- and across-flight directions by using a suitable window to reduce the effect of fading. Then we applied the preflight correction before making a histogram of the pixel values of the images to determine outliers. The outliers are either very weak (water) or very strong (some man-made objects) and thus should not be used. We define an outlier as a signal level outside a region bounded by the $1 \%$ levels on the main peak of the probability density function (27 dB in Fig. 2). Only homogeneous sections are used in the later averaging process. The next step is to undo the radiometric correction. This was easy because the radiometric corrections are provided in a table in the header of the image tape. Finally, we averaged the return powers along the flight lines (excluding outliers). Each line of the output image then becomes a single value corresponding to a particular range.

The radar equation may be simplified to

$$
P_{r}=\frac{K G^{2} \sigma^{0}}{R^{3} \sin \theta}
$$

where

$\mathrm{G}=$ Antenna Gain

$\sigma^{0}=$ Scattering Coefficient

$\mathrm{R}$ = Slant Range

$\theta=$ Angle of Incidence

$\mathbf{P}_{\mathbf{r}}=$ Return Power from the Target.

$\mathrm{K}$ is a constant containing all other factors that do not vary for the system. We may solve this equation for $G$ to obtain the pattern from the measured power.

Shimada and Freeman [6] suggested that additive noise should be included in the radar equation (which tends to narrow the retrieved beamwidth). However, the high SNR of the images we used (over $20 \mathrm{~dB}$ in most cases) made this unnecessary. Since the scattering coefficient does not vary significantly with angle over the rain forest, the only variables we need consider are $R, \theta$, and $P_{r}$. Using this concept, we obtain an antenna-gain pattern for each image. Finally, we fit a smooth function [i.e., $\cos ^{b}\left(c_{L}\right)$ where $b$ and $c$ are fitting parameters] to the resulting relative vertical antenna pattern $G_{(L)}$. From that function, we are able to calculate the 6-dB elevation beamwidth of the antenna.

\section{RESULTS}

Figure 1 shows the histogram of the pixel power return of image 78.60 after averaging to get a square pixel of about 200 
$x 200 \mathrm{~m}$. The outlier returns caused by the river and possible man-made objects show clearly on the histogram. We discarded these portions of the image in obtaining the pattern. Histograms for other images are similar to the one shown.

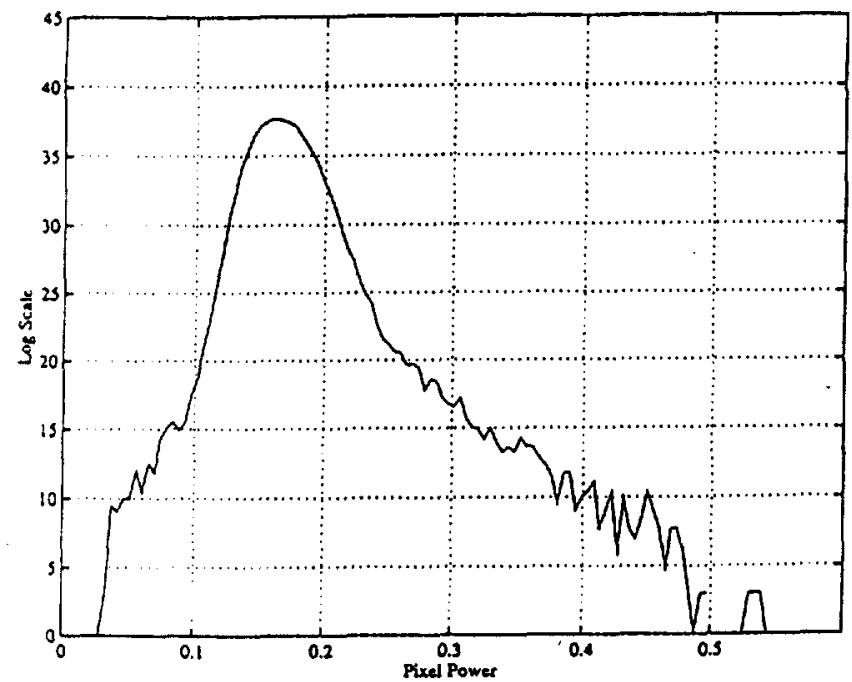

Fig. 1. The histogram of the images after being averaged by using $16 \times 16(200-\times 200-\mathrm{m})$ windows. From the histogram, we can clearly see the outliers and thus are able to determine the upper and lower boundaries for the outlier returns.

We used this technique to obtain the vertical antenna patterns for four scenes from the Amazon forest and then smoothed the patterns by fitting models to them. Three models tested are:
A) $G(\phi)=d \cos ^{b}(c(\phi-a))$
B) $\mathrm{G}(\phi)=b+c(\phi-a)^{2}$ and
C) $G(\phi)=b+c(\phi-a)^{2}+d(\phi-a)^{4}$

Model $C$ was used by [6]. We used a least-squares method to fit these functions to the measured pattern. For pass 103.60, product 12093, the results appear in Fig. 2. Model B (quadratic function) is too inflexible to cover all of the pattern shapes. Model C (quartic without the odd terms) fits reasonably well within the data region, but is unrealistic beyond the data points. Various experiments show that model A can fit most of the antenna patterns we encountered and works well both inside and outside the data region. Table 2 shows the fits and rms deviations for the three models.

Table 2. Fitting Results for Product 12903

\begin{tabular}{|c|c|c|c|c|}
\hline \multicolumn{2}{|c|}{ Anienna Pattern Model } & \multirow{3}{*}{$\begin{array}{c}\text { Beamwidth } \\
\text { (degrecs) }\end{array}$} & \multicolumn{2}{|c|}{ Error RMS Devialion } \\
\hline & & & \multirow{2}{*}{$\frac{\text { verical (dB) }}{0.01}$} & \multirow{2}{*}{$\frac{\text { horizontal (deg) }}{0.01}$} \\
\hline & 3.dB down & & & \\
\hline$d \cos s^{*}(c(\cdot a))$ & 6.dB down & 4.85 & 0.01 & 0.02 \\
\hline \multirow[b]{2}{*}{$b+c(-a)^{2}$} & 3-dB down & 4.44 & 0.91 & 0.46 \\
\hline & 6-dB down & 5.26 & 0.84 & 0.39 \\
\hline \multirow[b]{2}{*}{$b+c(-a)^{2}+d(-a)^{4}$} & 3-dB down & 3.57 & 0.06 & 0.03 \\
\hline & 6-dB down & 4.79 & 0.05 & 0.04 \\
\hline
\end{tabular}
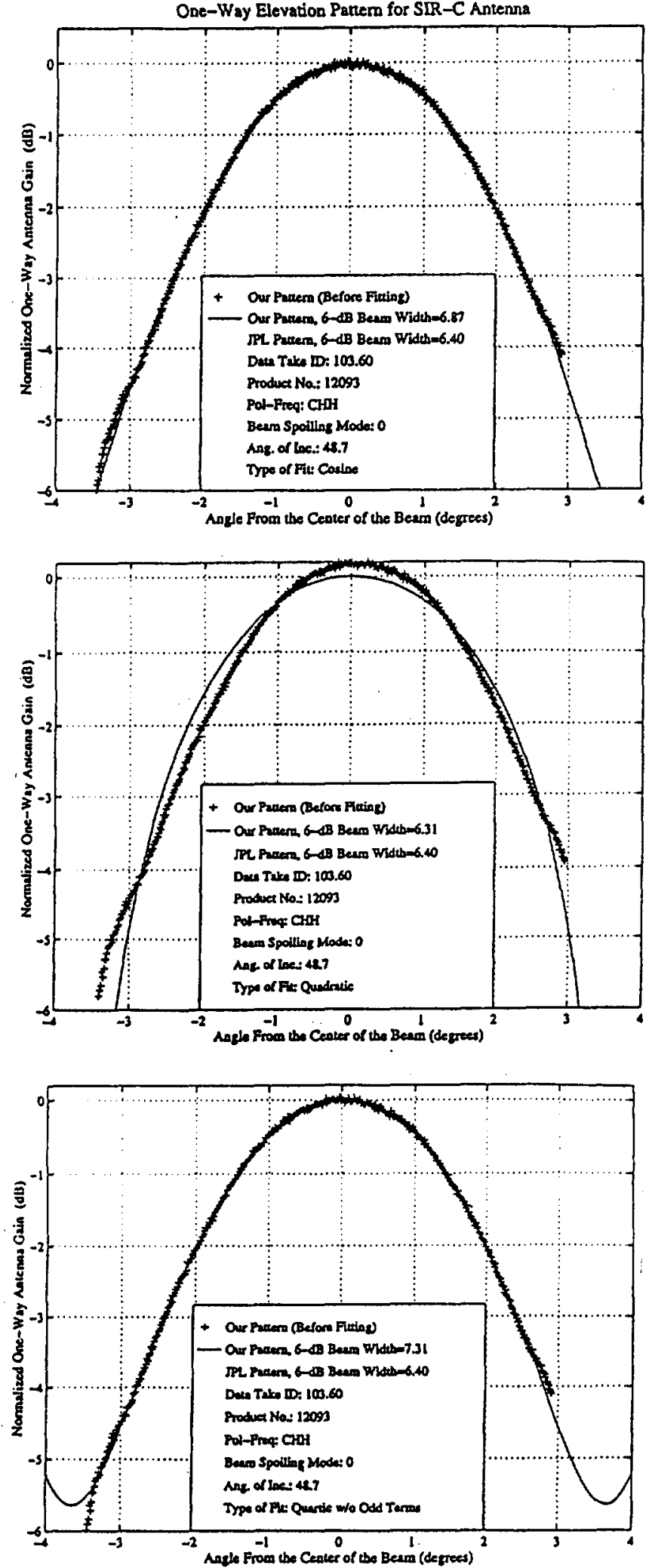

Fig. 2. Resulting patterns for prod. 12093 by using 3 different fitting models. The fitting models used are (a) cosine function, (b) quadratic function and (c) quartic function. 

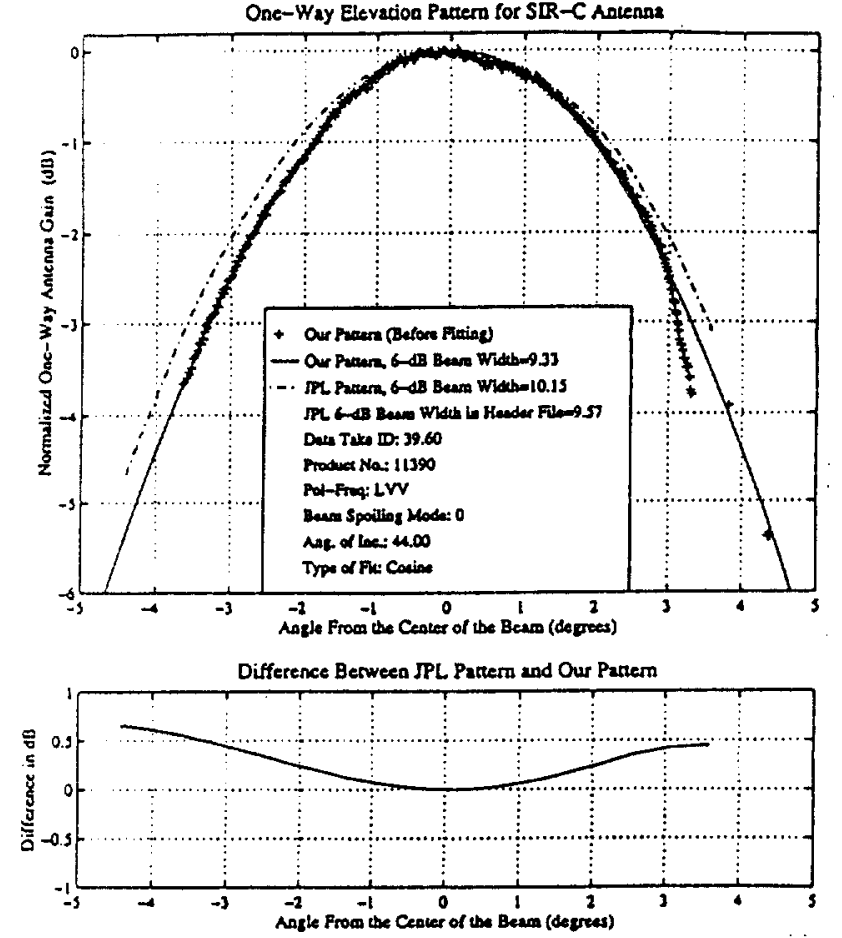

Fig. 3. Example of the composite plots for two-way relative elevation antenna patterns extracted from SIR-C images, no beam spoiling.

The overall results are shown in Fig. 3 for Data Take 39.60, L band, Product 11390. In this case, our pattern and the preflight pattern agree reasonably well. Fig. 4 shows a case where beam spoiling Mode 6 was used (Pass 78.60, Product 12348). In this case the results differ significantly between the measured pattern from the Amazon, the preflight JPL pattern, and the beamwidth shown on the header. Overall results for all passes used are summarized in Table 3. Without beam spoiling our pattern and the JPL preflight pattern (extracted from the radiometric correction table) agree reasonably well. However the difference is large for the beam-spoiling modes, such as mode 6 (in some cases it can be as big as $1 \mathrm{~dB}$ beyond $3^{\circ}$ from the center of the beam). This result confirms that the radiometric calibration provided with the images can give a relatively large error when the $6-\mathrm{dB}$ beamwidth exceeds $17^{\circ}[7]$. Moreover, the beamwidths given in the tape header are often significantly differently than the beamwidths extracted from the radiometric correction table.

\section{CONCLUSION}

The in-flight vertical pattern of the SIR-C antenna agreed well with the preflight pattern used for radiometric correction for most of the cases studied. However, for Pass $\mathbf{7 8 . 6 0}$ where beam spoiling was used, our best fit is much narrower than that given by the radiometric correction, and much wider than that listed in the tape header. This case contains only a small pattern segment, which may contribute to this discrepancy.

We believe the beam patterns determined by this method should be used in subsequent data analysis. They should represent the true in-flight pattern better than any ground measurements. Unfortunately, the improved patterns are only available for a small fraction of the total complex of SIR-C patterns. Users who need good radiometric data for their applications should consider using only passes without beam spoiling. If radiometric accuracy is not important for an application, beam-spoiled images may be adequate.

\section{ACKNOWLEDGMENTS}

This work was supported by NASAJPL under contract 958434. Many JPL personne were very helpful for providing the image data and detailed information about the data iormat.
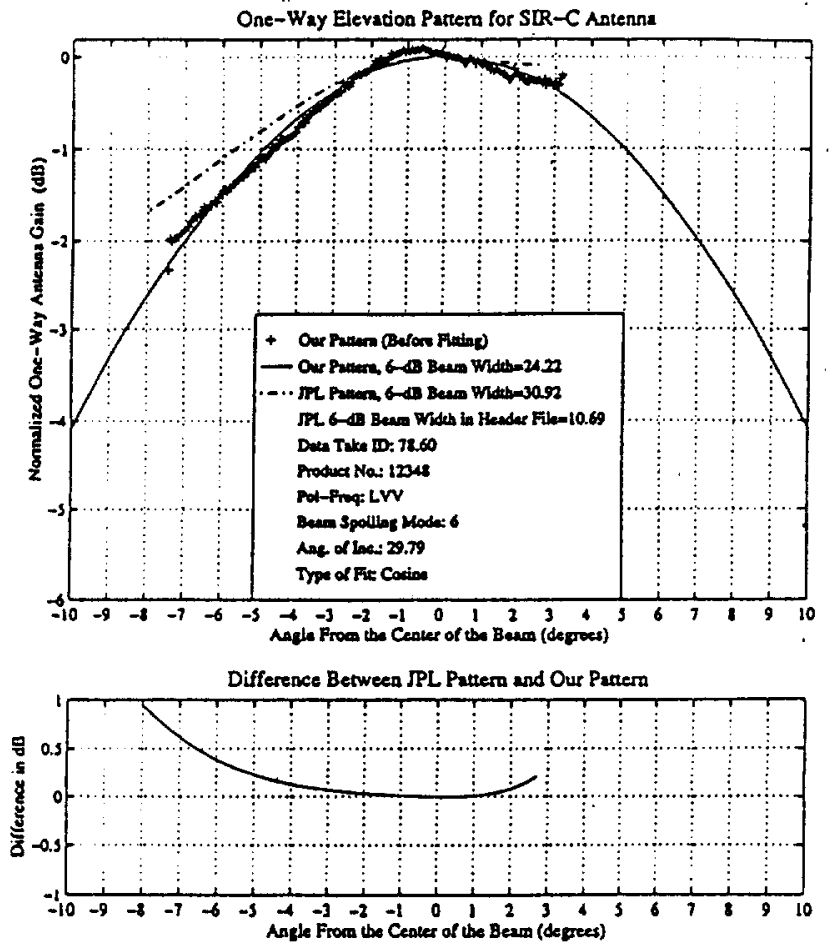

Fig. 4. Example of the composite plots for 2-way relative elevation antenna patterns extracted from SIR-C image, Mode 6 beam spoiling.

Table 3. Summary of Results ${ }^{1}$ [' All the results are obtained by using cosine fit; ${ }^{2}$ Incident angle are defined at the center of the image; ${ }^{3}$ The data in the radiometric correction table was extended by using cosine fit.]

\begin{tabular}{|c|c|c|c|c|c|c|c|}
\hline $\begin{array}{l}\text { Prod. } \\
\text { ID }\end{array}$ & $\begin{array}{l}\text { Data } \\
\text { Take } \\
\text { ID }\end{array}$ & $\begin{array}{l}\text { Beam } \\
\text { Spoil. } \\
\text { Mode }\end{array}$ & $\begin{array}{l}\text { Beam } \\
\text { Steer. } \\
\text { Angle }\end{array}$ & $\begin{array}{l}\text { Inc. }{ }^{2} \\
\text { Angle }\end{array}$ & $\begin{array}{l}\text { Freq. } \\
\text { Pol. }\end{array}$ & $\begin{array}{c}\text { Our 6-dB } \\
\text { BeamWidth }\end{array}$ & $\begin{array}{l}\text { JPL 6-dB } \\
\text { Beanwidth } \\
\text { (Rad. Corr.) }\end{array}$ \\
\hline \multirow[b]{2}{*}{11389} & \multirow[b]{2}{*}{39.60} & \multirow[b]{2}{*}{0} & \multirow[b]{2}{*}{$2.2^{\circ}$} & \multirow[b]{2}{*}{$44.0^{\circ}$} & LVV & $6.77^{\circ}$ & $7.30^{\circ}$ \\
\hline & & & & & LHH & $6.76^{\circ}$ & $7.16^{\circ}$ \\
\hline \multirow[b]{2}{*}{11390} & \multirow[b]{2}{*}{39.60} & \multirow[b]{2}{*}{0} & \multirow[b]{2}{*}{$2.1^{\circ}$} & \multirow[b]{2}{*}{$44.0^{\circ}$} & LVV & $6.67^{a}$ & $7.27^{\circ}$ \\
\hline & & & & & LHH & $6.62^{\circ}$ & $7.06^{\circ}$ \\
\hline \multirow[b]{2}{*}{11342} & \multirow[b]{2}{*}{55.62} & \multirow[b]{2}{*}{0} & \multirow[b]{2}{*}{ I4.T } & \multirow[b]{2}{*}{$26.3^{\circ}$} & CVV & $8.08^{\circ}$ & $6.95^{\circ}$ \\
\hline & & & & & $\mathrm{CHH}$ & $7.31^{\circ}$ & $6.98^{\circ}$ \\
\hline \multirow[b]{2}{*}{12347} & \multirow[b]{2}{*}{78.60} & \multirow[b]{2}{*}{6} & \multirow[b]{2}{*}{$11.3^{\circ}$} & \multirow[b]{2}{*}{$29.8^{*}$} & LVV & $16.75^{\circ}$ & $21.58^{\circ}$ \\
\hline & & & & & LHH & $17.44^{\circ}$ & $21.51^{\circ}$ \\
\hline \multirow[b]{2}{*}{12348} & \multirow[b]{2}{*}{78.60} & \multirow[b]{2}{*}{6} & \multirow[b]{2}{*}{$11.3^{*}$} & \multirow[b]{2}{*}{$29.8^{\circ}$} & LVV & $15.00^{\circ}$ & $21.58^{\circ}$ \\
\hline & & & & & LHH & $16.29^{\circ}$ & $22.30^{\circ}$ \\
\hline 12,092 & 103.6 & 0 & $6.4^{\circ}$ & 48.7 & $\mathrm{LHH}$ & $4.85^{\circ}$ & N/A \\
\hline 12,093 & 103.6 & 0 & $6.4^{\circ}$ & $48.7^{\circ}$ & $\mathrm{CHH}$ & $4.67^{\circ}$ & N/A \\
\hline
\end{tabular}

[1] A. Sobti and E. C. Davison, "Microwave scattering measurements over Brazil at $13.9 \mathrm{GHz}$," RSL Technical Report 243-11, Radar Systems \& Remote Sensing Laboratory, Lawrence KS, Univ, of Kansas, 1975.

[2] I. Birrer, E. Bracalente, G. Dome, J. Sweet, and G. Berthold, " $\sigma$ " signature of the Amazon rain forest obtained from the Seasat scatterometer," IEEE Trans.Geosci.Rem.Sens., vol. GE-20, pp. 11-17, 1982

[3] R. L. Jordan, B. L. Huneycutt, and M. Werner, "The SIR-CIX-SAR synthetic aperture radar system," IEEE Trans. Geosci. Rem. Sens., vol. GE-33, pp. 829-839, 1995.

[4] R. K. Moore and M. Hemmat, "Determination of the vertical pattern of the SIRB antenna," Int.J.Remote Sensing, vol.9, pp.839-847, 1988.

[5] Y. Fang and R. K. Moore, "Inflight vertical antenna patterns for X-SAR from Amazon rain-forest observations," IEEE Trans. Geosci. Rem. Sens., vol. GE-33, pp. 1083-1085, 1995.

[6] M. Shimada and A. Freeman, "A technique for measurement of spaceborne SAR antenna patterns using distributed targets," IEEE Trans. Geosci. Rem. Sensing. vol. 33, pp. 100-114, 1995.

[7] A. Freeman, M. Alves, B. Chapman, J. Cruz, Y. Kim, S. Shaffer, J. Sun, E. Turner, and K. Sarabandi, "SIR-C data quality and calibration results," IEEE Tnans. Geosci. Rem. Sens. vol. 33, pp. 848-857, 1995. 